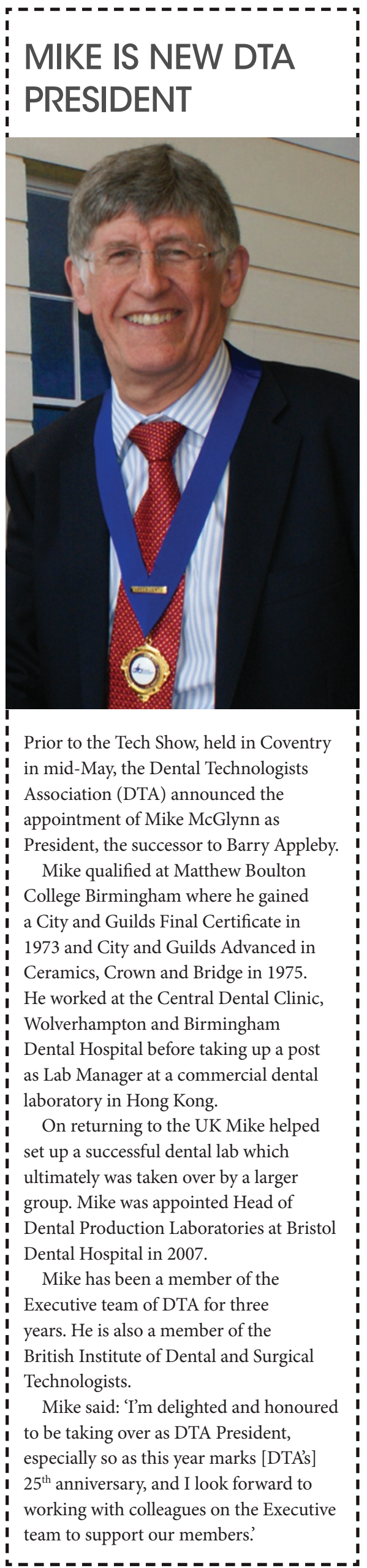

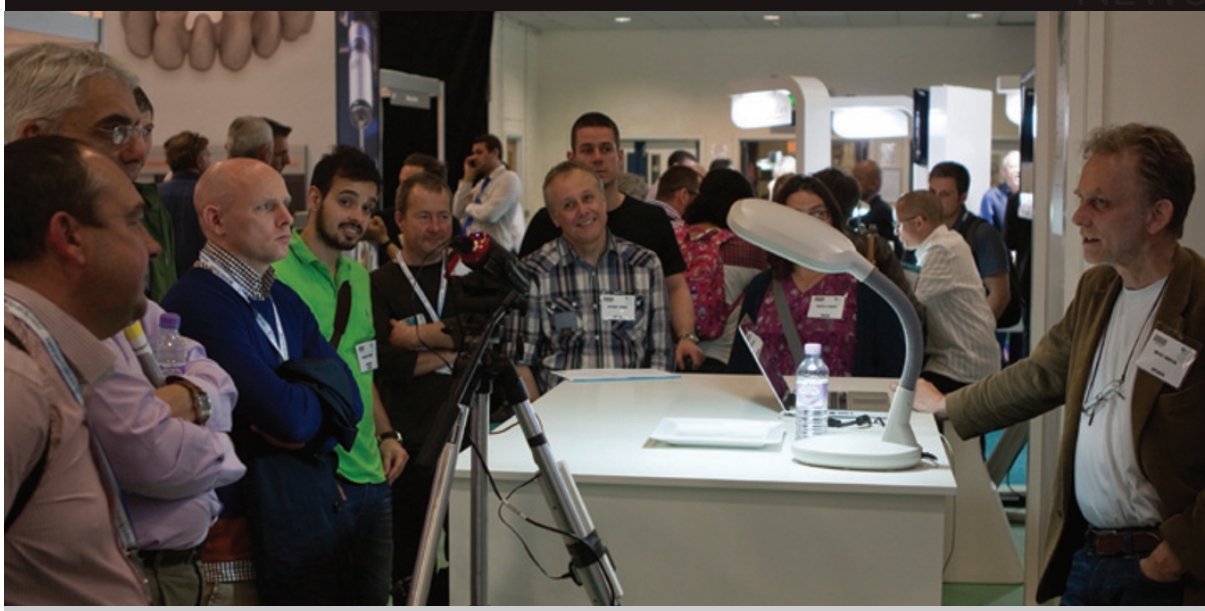

TECHNICIANS AND LAB OWNERS FLOCK
TO TECH SHOW

Hundreds of dental technicians, laboratory owners and clinical dental technicians (CDTs) attended the British Dental Industry Association (BDIA) Tech Show in May, a new venture for the BDIA run in partnership with the Dental Technologists Association (DTA).

Delegates sampled a selection of over 60 live demonstrations and talks, hands-on masterclasses, a trade exhibition and lectures from world class speakers at Coventry's Ricoh Arena.

Tech Show offered arguably the widest scope of any technician-facing event in the UK for many years. DTA President Mike McGlynn said: 'We were delighted to be part of Tech Show which offered so many fascinating and insightful sessions to visitors, combined with the opportunity to meet their favourite suppliers, watch the product demonstrations and learn about many new products and systems'.

Tech Show exhibitors took full advantage of the event with a range of new product launches and an array of stands and product displays, including the milling, digital printing and imaging technologies that are revolutionising laboratory work.

BDIA Executive Director Tony Reed said: 'Tech Show indicates that there are clear distinctions between what different members of the dental team want and require from dental shows. Our Tech Show experience demonstrated that technicians are interested in close-up, practical demonstrations with interactive activities and hands-on involvement?

Did you attend Tech Show? What did you think of the event?Email bdjteam@ nature.com.

\section{DCPs MAD FOR \\ MANCHESTER 2014}

Over 1,000 dental care professionals (DCPs) attended this year's British Dental Conference and Exhibition in Manchester: record attendance for both the Thursday and the Friday of the event.

The lecture programme at the conference included a number of sessions specifically aimed at the dental team, including: how skill mix can be used to increase success and profitability; working safely within your scope of practice; the new GDC standards; caring for patients with dementia; and safeguarding vulnerable children.

Visitors to the Exhibition had access to over 150 exhibitors as well as the Innovation Zone; BDA Museum cinema; the Training Essentials theatre and the live Demonstration theatre.
In the Training Essentials theatre the dental team had a lot to choose from with over 20 sessions covering core CPD subjects, regulatory updates and personal development. Highlights for DCPs included a session hosted by the British Association of Dental Therapists (BADT) looking at the latest research into the role DCPs can play in screening for common oral diseases, and sessions on dental photography, periodontics, radiography, and child safeguarding.

Thursday evening drinks in the exhibition hall offered an opportunity to informally network with exhibitors whilst a sold out Friday night party saw guests enjoying the sounds of live band Hipster.

Planning has already begun for next year's event: 7-9 May 2015 in Manchester.

For photos of this year's event see www. facebook.com/thebritishdentalassociation. 